\title{
Application of Computer Technology in Aesthetic Education and Feature Analysis
}

\author{
https://doi.org/10.3991/ijet.v14i14.10713 \\ Lina An \\ Northeast Agricultural University, Harbin, China \\ 78809335 @qq. com
}

\begin{abstract}
The synergetic development of art and technology is a common trend for the development of aesthetics and computer technology, so it is imperative to introduce computer technology to aesthetic education in Chinese colleges. This paper reviews the problems and dilemma of college aesthetic education in China and proposes to reform college aesthetic education by information technology. Focusing on image aesthetics, the author analyzes the image aesthetic features with computer algorithms and demonstrates the superiority of computer algorithms in optimizing image and enhancing aesthetic beauty. The proposed method can overcome the dilemma of aesthetic education in Chinese colleges and realizes preliminary informatization reform of college aesthetic education. The research findings have theoretical guiding significance for the modernization of aesthetic education in colleges and the comprehensive development of college students.
\end{abstract}

Keywords - Computer technology, aesthetic education, image aesthetics, education reform

\section{Introduction}

\subsection{Applying the styles to an existing paper}

The application of computing technology in various industries has become more extensive and deeper, and the application of computer technology in college education has improved teaching efficiency and learning effect in teaching practice. With the advent of digital and big data era, computer technology will raise a huger wave of reforms to college education and will be integrated into the teaching of various fields [1]. Aesthetic education is related to art, aesthetics, and other sentimental emotional experiences; therefore, it has a low degree of association with informatization and digitization. At this stage, the college aesthetic education has the shortcomings of irregular and random, so a more advanced teaching method is required to promote its development towards a refined, quantitative and rational direction [2].

The integration of computer technology and aesthetic education has built a bridge for the development of aesthetics from qualitative analysis to quantitative analysis. The quantitative analysis can bring more concrete and rational cognition to aesthetic 
education and promote the creation of new designs and ideas [3]. Under the influence of traditional Chinese aesthetics, the relationship between technology and art has been attenuated. However, in recent years, the research idea of combing art with technology to create aesthetic values and applicable values has been gradually accepted in the industries, and corresponding researches have been carried out: some scholars have analyzed the quantitative educational problems of design aesthetics from the perspective of digitalization, and summarized main principles for computer design aesthetic education; some scholars adversely applied the aesthetic ideas to the teaching of computer science, aiming to make the computer classes more interesting and diversified; and there are also some scholars who have used computer methods to simulate the aesthetic evaluation and classification of images by human aesthetic senses, achieving a higher similarity of image aesthetic perception [4]. Through the studies of scholars and with the maturing of computer technology and information technology, the application of computer technology in college aesthetic education is imminent.

This paper innovatively proposes to apply computer technology into aesthetic education practice and aesthetic characteristics analysis. Firstly, through the induction and analysis of the problems existing in the current college aesthetic education, the paper puts forward policies for computer reforms, and then demonstrates the advanced nature of computer technology in aesthetic education through the method of applying computer technology for the optimization of image aesthetics; at last, based on computer technology, it proposes reform strategies based on computer technology, aiming at improving the teaching level of aesthetic education in Chinese colleges and cultivating well-rounded college students.

\section{Aesthetic Education of College Students}

\subsection{Category of aesthetic education of college students}

Aesthetic education refers to the dissemination of beautiful things to the audiences through different media according to the aesthetic consciousness, and the audiences expect to enjoy themselves and cultivate their sentiment through aesthetic education, and improve their ability to discover beauty and create beauty. College aesthetic education is not only limited to art major college students, but aiming to improve the aesthetic literacy of college students of all majors and perfect their personality and values [5]. The dissemination carriers of aesthetic education of college students include college public classrooms, college students' art elective courses, campus cultures, and campus art festivals, etc.

The role of aesthetic education of college students includes:

- Through aesthetic education of college students, cultivate sentiments, restrain emotions, enhance individual comprehensive qualities, establish noble aesthetic sentiments, correct aesthetic concepts and healthy aesthetic tastes.

- The aesthetic education of college students is not only the cultivation of college students' personal accomplishment, but also the perfection of their personality 
through aesthetic education, so as to truly shape and perfect the ideal personality of their pursuit, and to promote the comprehensive, free and harmonious development of college students [6].

- Improve the adaptability of college students to the college life and learning, thereby cultivating their adaptability to the society, as well as their emotional intelligence and comprehensive abilities.

\subsection{Dilemma in aesthetic education of college students}

Through the online investigation of the aesthetic education in 20 colleges and universities in China and interviews with some teachers and students, the author.

Weakening of college students' aesthetic abilities

Lack of cognitive ability: At the present stage, most college students' cognition of beauty is in an isolated and weakened status, the distorted aesthetic emotions have limited their aesthetic feelings and aesthetic effects. Due to the lack of systematic cognition and experience of beauty, college students' understanding of beauty is too simple, resulting in the weakening of the aesthetic abilities [7].

Weakened ability to identify beauty: Due to the influence of vulgar cultures on the Internet, superficial matters and shallow things such as online celebrities have distorted the aesthetic concepts of college students. Since they lack the ability to identify true beauty, most college students' aesthetic ability is too low to judge and resist the contents spread on the internet.

Weakened ability to create beauty: The reduction in the cognitive ability and discernment weakens college students' collective ability to create beauty, which is reflected in the decrease of college students' interest in discovering and creating beauty.

Deviation of college students' aesthetic values: In simple words, aesthetic values are the personal attitudes toward ugliness, beauty, goodness and evil. Due to the influence of western thoughts and negative online opinions, the aesthetic values of contemporary college students have deviated to a certain extent, showing the trends of money-centered, sentimental and vulgar, mainly manifested in: money worship is popular, which believes that beautiful things must be related to the money; vulgar and superficial novels, films and television works are touted, while classical and profound literatures and arts are rarely known; in terms of aesthetic expression methods, profound and euphemistic expressions are replaced by rude and abrupt expressions; and the popularity of instant-ism has made students' lives further down the path of vulgarization [8].

Poorly implemented college student aesthetic education curriculum and practical activities: Through investigation, it is found that the current college aesthetic education in China has problems such as improper curriculum arrangement, lack of new ideas and attractiveness, low curriculum requirements, less practical activities, insufficient teacher-student interactions, etc., which is also the fundamental root for the dilemma of college aesthetic education in China.

Table 1 shows a summery of the problems existing in the classroom arrangement of college aesthetic education. 
Table 1. Problems in classroom arrangement of college aesthetic education

\begin{tabular}{|c|l|c|}
\hline Problems item & \multicolumn{1}{|c|}{ Problem content } & Percentage \\
\hline 1 & $\begin{array}{l}\text { The university has not yet established a perfect aesthetic education curriculum } \\
\text { system. }\end{array}$ & $50 \%$ \\
\hline 2 & $\begin{array}{l}\text { The number of aesthetic education courses in colleges is small, mainly in the } \\
\text { form of elective courses, and the penetration rate is low. }\end{array}$ & $70 \%$ \\
\hline 3 & $\begin{array}{l}\text { The content of the aesthetic education curriculum is boring, lacks the charac- } \\
\text { teristics of the times, and lacks aesthetic materials that meet the needs of } \\
\text { students. }\end{array}$ & $80 \%$ \\
\hline 4 & $\begin{array}{l}\text { The construction of the faculty of aesthetic education is imperfect, the teach- } \\
\text { ing methods and courses are relatively old and lack new ideas. }\end{array}$ & $90 \%$ \\
\hline
\end{tabular}

- Deficiencies in classroom arrangement of college aesthetic education: It can be seen that the aesthetic education has fewer class hours, the popularization rate is low, the content of aesthetic education is outdated, the teaching materials are not in line with the characteristics of the times, the aesthetic education teachers are of low quality, their professional level is low, and the teaching mode of aesthetic education is still the spoon-feeding style which is lack of attractiveness. All these reasons have caused the dilemma of college aesthetic education [9].

- Deficiencies in practice of aesthetic education: The aesthetic education practice of colleges and universities includes campus culture festivals, students' social practices, and the like, which are extensions of aesthetics classroom education and carriers to improve college students' aesthetic consciousness. Through chorus competitions, evening shows, volunteer teaching programs, art exhibitions, concerts, and other forms that can cultivate students' sentiments, the students' vision could be broadened, their aesthetic sentiment could be cultivated, and their overall quality could be improved. Through investigation, it summarizes three main problems in the practice of aesthetic education in colleges and universities at the current stage [10].

The teaching practice of aesthetic education has presented a tendency of utilitarianism, students participate in the teaching practice of aesthetic education with the purpose of fulfilling the tasks assigned by the class or the school.

The awareness of college aesthetic education practice is weakened. With the decline of aesthetic education classes, the teaching practice of aesthetic education in colleges and universities is becoming less appreciated, and this situation is more prominent in little-known colleges and universities. The aesthetic practice of colleges and universities is the main way to spread the campus culture, without it, the students' aesthetic quality and aesthetic values begin to deviate.

Aesthetic education presents a professional trend. In the investigation of some colleges and universities, it's found that the idea of "aesthetic education is only a matter for art major students and has nothing to do with non-art major students." still exists, resulting in non-art major students seldomly participate in practical activities of aesthetic education, and the popularity of aesthetic education practice is reduced.

In the dilemma of aesthetic education, college students have poor aesthetic abilities and values is the result, and the college students' aesthetic education classes and prac- 
tical activities are insufficient is the fundamental reason. Only by seizing the roots of the problems can we improve and reform the aesthetic education classes for college students and carry out practical activities, so as to truly realize the improvement of aesthetic education levels.

\section{Application of Computer Technology in Feature Analysis of Aesthetic Education}

This paper attempts to introduce computer technology to reform the college aesthetic education classes and teaching practical activities, enrich teaching methods and improve teaching effects. This paper studies the application of computer technology in image aesthetics feature analysis and composition optimization processing, aiming to use computer technology to enhance image aesthetics, and thereby demonstrating the feasibility and scientificity of the integration of computer technology and aesthetics.

\subsection{Computer image aesthetic composition optimization}

Image composition optimization is a method that achieves image content reoptimization and re-organization according to algorithms and composition principles to improve image aesthetics. The core technology is to use computer technology to express the quantized calculation formulas and constraints through computer language and adjust the image layout by inputting condition variables to improve the aesthetics of images.

\section{Principles of image aesthetics}

The rule of thirds: The rule of thirds is a commonly-used principle for image composition. Its core technical route is to divide an image into 9 squares using two vertical lines and two horizontal lines, wherein the 4 cross points are the focus points in image aesthetics. The rule of thirds believes that when the subject of the image is at the focus point, the image's aesthetic feeling is better. Figure 1 is an example for the rule of thirds in image aesthetics.

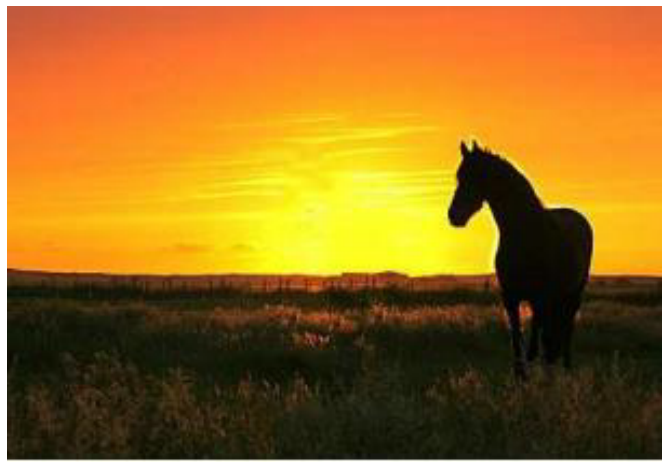

Fig. 1. An example for the rule of thirds in image aesthetics 
The rule of visual balance: The rule of visual balance believes that there are three golden ratios for the image subject in a whole image: $0.1,0.56$, and 0.8 , when the image subject is of these ratios, the image could reach the visual balance.

Computer image processing methods: The computer image composition optimization processing methods mainly include the image restoration method and the image re-mapping method. This paper adopts the image re-mapping method to conduct mesh deformation so as to make sure the image details are not distorted as much as possible and perform mesh optimization processing according to image aesthetic principles. Using computer language, the calculation formulas of the composition energy function, the constraint conditions, the quadratic programming, and the image deformation algorithm are integrated into the $\mathrm{C}++$ computer language, constructing the computer image composition optimization program.

Comparative analysis of image aesthetics composition optimization experiment: Figure 2 and Figure 3 show the comparison of two sets of original images

- Gallea image processing methods

- And computer mesh optimized compositions [11].

It can be seen from the comparison of the processing results of the two sets of images that, although the Gallea method has improved the resolution of the images, the cropping of the image has resulted in the loss of image information, which reduces the aesthetic feeling of the images; while the computer mesh composition optimization method has recomposed the images according to image aesthetic principles under the premise of preserving the subjects of the images, which enhances the aesthetic feeling of the images, and better processes the integrity and clarity of the images.

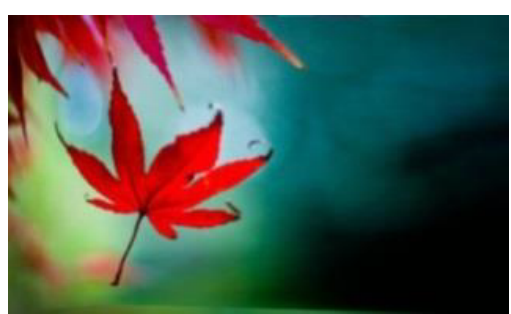

a)

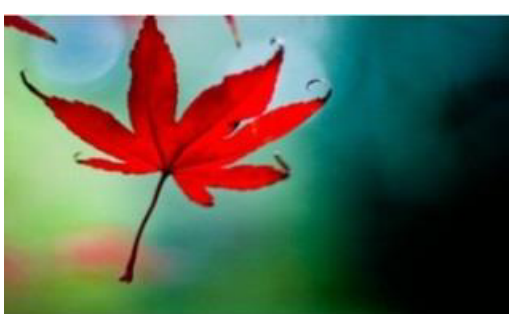

b)

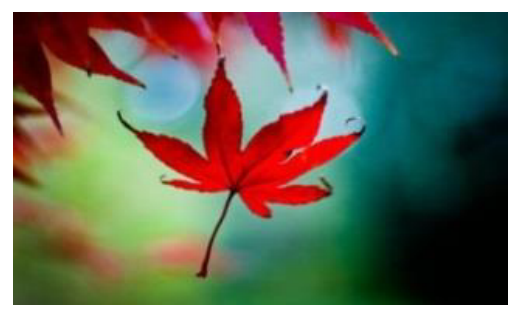

c)

Fig. 2. Image processing result example one 


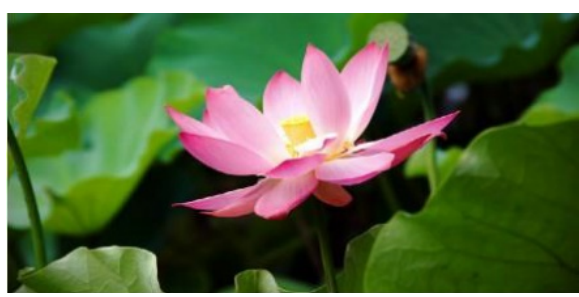

a)

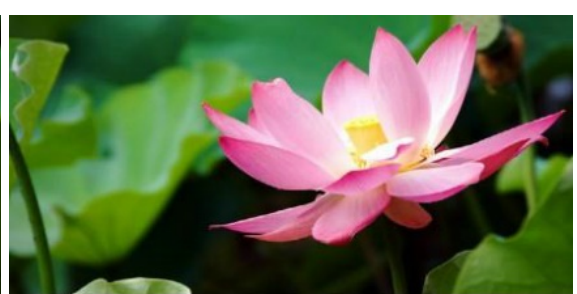

b)

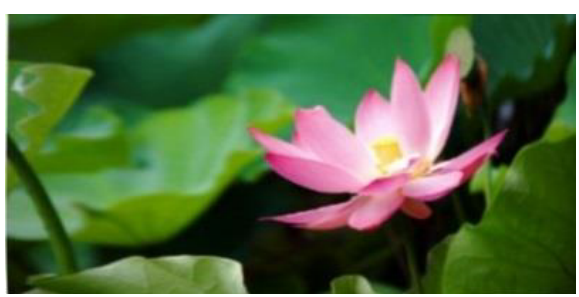

c)

Fig. 3. Image processing result example two

\subsection{Computer image feature analysis and scoring technologies}

In existing research results, the computer image aesthetic classification and evaluation technologies achieved the goal of image aesthetic feeling automatic evaluation via steps of extraction of image key areas and features (color, shape, texture), and construction of aesthetic classification and evaluation models, etc., and the algorithm has good regression performance and accuracy [12]. Taking photos from the image library of photos.net that have been scored by people on its aesthetic feelings as the research subjects, the computer image aesthetics automatic evaluation experiment was conducted using multiple computer image aesthetic classification and evaluation technologies.

Table 2. Comparison of classification performance of different methods

\begin{tabular}{|l|c|c|c|c|c|c|}
\hline \multirow{2}{*}{ Classification result } & \multicolumn{2}{|c|}{ Technique 1 } & \multicolumn{2}{c|}{ Technique 3 } & \multicolumn{2}{c|}{ Technique 3 } \\
\cline { 2 - 7 } & High beauty & Low beauty & High beauty & Low beauty & High beauty & Low beauty \\
\hline High beauty & 73.20 & 26.80 & 75.47 & 24.53 & 77.60 & 22.40 \\
\hline Low beauty & 37.73 & 62.27 & 29.19 & 70.81 & 26.86 & 73.14 \\
\hline Average Accuracy & \multicolumn{3}{|c|}{67.74} & \multicolumn{2}{c|}{73.14} & \multicolumn{2}{c|}{75.37} \\
\hline
\end{tabular}

Table 2 shows the computer technology evaluation results of crossed confusion matrix, the accuracy rates of the three kinds of computer image aesthetic classification and evaluation technologies were $67.74 \%, 73.14 \%$, and $75.37 \%$, respectively. From the evaluation of the high aesthetic feeling images and low aesthetic feeling images we can see that, the computer technologies have already equipped with aesthetic cognition that is consistent with human aesthetics through the excellent machine learning methods, indicating that the computer technologies can perform preliminary screening or pre-processing on images that require aesthetic evaluation. 


\section{$4 \quad$ Practice of the Integration of Computer Technology and Aesthetic Education}

\subsection{Integration of computer technology and aesthetic education}

Computer technology, including computer image processing technology, artificial intelligence technology, and image composition optimization technology, etc., are all helpful to people's aesthetic activities. The essence of aesthetic education for college students is the teaching and learning of aesthetic cognition and artistic experiences. Therefore, as typical representatives of technology and art, computer technology and college aesthetic education have good development prospects. Figure 4 shows the strategic map of the integration of computer technology and aesthetic education.

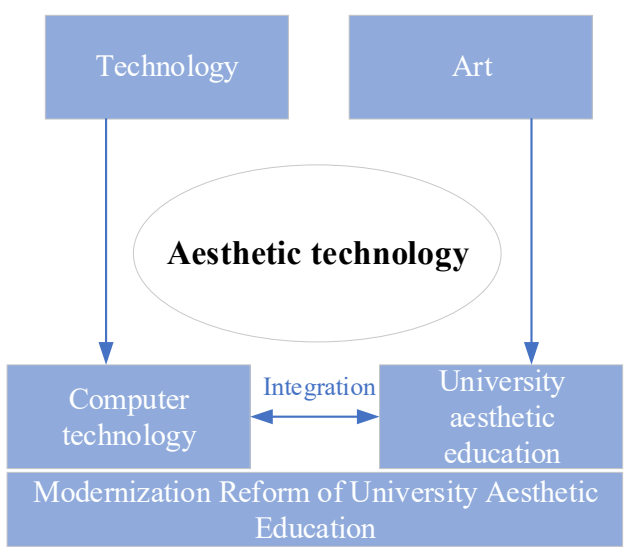

Fig. 4. Development strategy map

\subsection{College aesthetic education reform strategies based on computer technology}

The main idea of college students' aesthetic education reform is to adopt the advanced computer technologies to improve the popularity of aesthetic education courses, enrich course content, improve interactive frequency, and provide a broader platform for the practical activities of aesthetic education.

Improve the popularization of general aesthetic education classrooms based on computer technology: The common classrooms for aesthetic education are the public classrooms of higher education in colleges and universities. Only by using computer multimedia technology and image recognition technology to open more aesthetic education classrooms on campus to improve the possibility of students' contact with aesthetics, could we be able to improve the aesthetic level and aesthetic values of college students [13]. With the basic knowledge of aesthetic education as the main content, we should popularize the aesthetic education courses that aim to shape aesthetic consciousness, develop aesthetic ability, improve aesthetic perfor- 
mance, and promote aesthetic creation. In the form of public courses, we could incorporate the general aesthetic education courses into the general course system of the colleges and universities, and these courses have the characteristics of universal and extensive. Constructing a scientific general aesthetic education course system is the premise and foundation for effectively promoting the development of aesthetic education.

Promote the opening of diversified aesthetic education classrooms: The opening of diversified aesthetic education classrooms is mainly implemented from two perspectives:

- Open public courses and elective courses, forming a multi-curriculum system to facilitate students to choose different aesthetic education classes according to their actual interests and hobbies, and in these classes, properly apply computer technologies to assist the realization of the diversified aesthetic education classes;

- For the aesthetic education classroom teaching content, in addition to traditional teacher explanations and lectures, we can use computer multimedia, computer network and other technologies to open aesthetic education courses of different teaching content to increase the diversity of the teaching content, improving the interest in aesthetic education [14].

In terms of education method, the general aesthetic education courses must adhere to the combination of theory and practice. The goal of aesthetic education is not only to let students understand the knowledge of aesthetics, but also cultivate their abilities to perceive beauty and create beauty in educational activities. The traditional classroom only emphasizes theoretical knowledge and neglects the subjective initiative of the students; therefore, it has not achieved the expected educational effect. The general aesthetic education courses carry out activities with characteristics of practical, autonomous, creative and interesting, allowing students to experience beauty and learn the ability to create beauty. General aesthetic education courses should contain the transfer of knowledge and the cultivation of skills, as well as the transform of aesthetic ideas and the training of practical abilities [15]. In terms of the textbooks of aesthetic education, the textbooks of the general aesthetic education courses need to meet the training objectives of current domestic colleges and universities and the actual needs of college students. The western aesthetic education theoretical system is relatively rich and mature, by analyzing and concluding the western aesthetic education theories, we can recognize the advantages and disadvantages of western aesthetic education. We could combine with the traditional Chinese culture to form localized theories with Chinese characteristics. In the selection, organization and edition of the content of the teaching materials, we must pay attention to practical knowledge, as well as ensure the effective teaching of practical experiences. The aesthetic education textbooks should explain the profound theories in simple language and pay attention to the combination of practicality and readability of the knowledge, aiming to help students establish a healthy and good aesthetic concept, and cultivate their abilities to discover beauty, perceive beauty and create beauty.

Improve teachers' skill level in computer technology: Teachers are the most critical link in the successful reform of college aesthetic education and computer 
technology. At present, our country has attached more importance to the college aesthetic education, and the quality of college aesthetic education teachers is on the rise. In the process of teaching implementation, teachers should make use of the advanced computer technologies to improve their own quality and aesthetic taste and pass on the positive aesthetic energy and correct aesthetic values to college students through words and deeds.

Implement modern aesthetic education teaching practical activities: In the process of implementing college practical activities, we can provide college students with a publicity platform through computer technology to attract them to actively participate in various types of aesthetic education practical activities. At the same time, computer networks such as campus networks provide students with convenient communication opportunities and create an overall campus aesthetic education atmosphere, under which the students would be edified and influenced unwittingly.

\section{Conclusion}

The aesthetic education of college students is to promote the education of people with beauty, which is of great significance for college students to lay foundations for correct life outlook and values. At present, the aesthetic education of college students in China is in a difficult position, which requires a timely reform to help college students to correct the distorted aesthetic feelings and the deviated values. The integration and development of technology and art provides an opportunity for the reform of aesthetic education of college students. Therefore, this paper proposed the idea of reforming college students' aesthetic education based on computer technology. The main contents and significance of the study are concluded as follows:

- Through the online investigation, this paper summarized the current situation of college aesthetic education in China, analyzed the problems existing in the aesthetic education of Chinese colleges and universities, and proposed the idea of reforming college aesthetic education based on computer technology.

- With image aesthetics as the research subject, this paper illustrated the superiority of computer technology in image composition optimization and image aesthetic classification and demonstrated the possibility of applying computer technology in aesthetics.

- Based on computer technology, this paper proposed strategies to solve the dilemma of college aesthetic education in China.

- The research in this paper is of important theoretical significance for guiding the reform of aesthetic education of college students.

\section{References}

[1] Jacobsen, T., Schubotz, R. I., Höfel, L., Cramon, D. Y. (2006). Brain correlates of aesthetic judgment of beauty. Neuroimage, 29(1): 276-285. https://doi.org/10. $\underline{1016 / \text { j.neuroimage. } 2005.07 .010}$ 
[2] Krzywinski, M., Schein, J., Birol, I., Connors, J., Gascoyne, R., Horsman, D. (2009). Circos: an information aesthetic for comparative genomics. Genome Research, 19(9): 1639-1645. https://doi.org/10.1101/gr.092759.109

[3] Meijer, H. J., Stellingsma, K., Meijndert, L., Raghoebar, G. M. (2010). A new index for rating aesthetics of implant-supported single crowns and adjacent soft tissues--the implant crown aesthetic index. Clinical Oral Implants Research, 16(6): 645-649. https://doi.org/10. 1111/j.1600-0501.2005.01128.x

[4] Seng, D. W., Zhang, H. Q., Fang X. J., Zhang, X. F., Chen J. (2018). An improved fingerprint image matching and multi-view fingerprint recognition algorithm, Traitement du Signal, 35(3-4), 341-354.https://doi.org/10.3166/ts.35.341-354

[5] Pan, Z. C. (2016). Aesthetic dilemma in aesthetic education. Journal of Zhengzhou University. 5: 5-14,158.

[6] Zhou, Q. Y., Hu, X. Y. (2006). Toward the completeness of aesthetic education. Educational Research. 3: 39-43, 49.

[7] Smith, R. A. (2004). Aesthetic education: questions and issues. Arts Education Policy Review, 106: 16-16. https://doi.org/10.3200/AEPR.106.1.3-4

[8] Broudy, H. S. (1972). Enlightened cherishing: an essay on aesthetic education. Enlightened cherishing: an essay on aesthetic education. University of Illinois Press.

[9] Lou, S. Q. (2008). On the infiltration of aesthetic education in college english teaching. Journal of Nanyang Normal University, 8(4): 81-86.

[10] Laurent, M., Poljak, S. (2008). An 'aesthetic education': the role of 'sentiments' in the transition from traditional confucianism to modern aesthetics. Open Access Publications from Tilburg University, 17(3): 530-547.

[11] Shen, C. T., Liu, J. C., Shih, S. W., Hong, J. S. (2009). Towards intelligent photo composition-automatic detection of unintentional dissection lines in environmental portrait photos. Expert Systems with Applications, 36(5): 9024-9030. https://doi.org/10. 1016/j.eswa.2008.12.041

[12] Samii, A., Měch, R., Lin, Z. (2015). Data-driven automatic cropping using semantic composition search. Computer Graphics Forum, 34(1): 141-151. https://doi.org/10.1 $111 / \mathrm{cgf} .12465$

[13] Aguirre, I. (2010). Beyond the understanding of visual culture: a pragmatist approach to aesthetic education. International Journal of Art \& Design Education, 23(3): 256-269. https://doi.org/10.1111/j.1476-8070.2004.00405.x

[14] Greene, M. (1976). Literature in aesthetic education. Deutsche Medizinische Wochenschrift, 101(50): 1831-4. https://doi.org/10.2307/3332062

[15] Tokizawa, K., Onoue, Y., Uchida, Y., \& Nagashima, K. (2014). Ghrelin induces timedependent modulation of thermoregulation in the cold. Chronobiology International, 4(3), 83-88. https://doi.org/10.3109/07420528.2012.678452

\section{$7 \quad$ Author}

Lina An, graduated from art college of Harbin normal university, started work in 2006, lecturer of northeast agricultural university, choreographer of research direction, Email: 78809335@qq.com.

Article submitted 2019-04-19. Resubmitted 2019-05-27. Final acceptance 2019-05-27. Final version published as submitted by the authors. 